\title{
Estimation of radon concentration in dwellings in and around Guwahati
}

\author{
Gautam Kumar DeY* and Projit Kumar Das \\ Department of Physics, Pandu College, Guwahati 781 012, India. \\ *Corresponding author. e-mail: deygautam63@yahoo.com
}

It has been established that radon and its airborne decay products can present serious radiation hazards. A long term exposure to high concentration of radon causes lung cancer. Besides, it is also known that out of the total radiation dose received from natural and man-made sources, $60 \%$ of the dose is due to radon and its progeny. Taking this into account, an attempt has been made to estimate radon concentration in dwellings in and around Guwahati using aluminium dosimeter cups with CR-39 plastic detectors. Results of preliminary investigation presented in this paper show that the mean concentration is $21.31 \mathrm{~Bq} \mathrm{~m}^{-3}$.

\section{Introduction}

Radon $\left({ }^{86} \mathrm{Rn}^{222}\right)$ is a naturally occurring radioactive noble gas produced by the decay of radium226. It has a half-life of 3.825 days and disintegrates by emission of alpha particle of energy $5.5 \mathrm{MeV}$. Radon and its progeny are considered to be responsible for a significant dose to human beings, specially when they are in enclosed areas like underground mines, caves, poorly designed and badly ventilated houses. The measurement of radon concentration in the dwellings and in the environment are assuming ever increasing importance all over the world due to the fact that the inhalation of indoor radon and its short-lived daughters contribute a major fraction, nearly $60 \%$ of the total background radiation dose to the human being (UNSCEAR 1993).

The main source of indoor radon levels are the soil, building construction materials made commonly from the natural minerals such as sand, rock, cement (which contain the traces of $\mathrm{U}^{238}$, $\mathrm{Ra}^{226}$ ), tap water, natural gas used for cooking, etc. Radon is significantly influenced by the topography, house construction type and even the life style of the people. Radon in soil gas also depends on the radium content of the soil, soil density and the physical characteristics of the soil.

Radon estimation in soil gas, ground water and atmosphere is an established technique used in uranium exploration, domestic application and in earth-quake prediction. Its connection with uranium makes it useful in search of uranium ore and the inertness makes it an effective tracer that is useful in understanding geophysical processes that induce gas motion in the ground.

It is fairly established that there is an appreciable correlation between long term exposure to high concentration of radon and lung cancer (Archer et al 1973; Sevc et al 1988; Pershagen et al 1993) and kidney diseases (Waxweiler et al 1981). So the interest has been focussed on the measurement of radon inside the domestic premises. Large scale surveys of indoor radon levels have been undertaken in many countries soon after the incidental discovery of the Watras' house in December 1984 (Lowder 1989) in eastern Pennsylvania with radon concentrations in the region of $100,000 \mathrm{~Bq} \mathrm{~m}{ }^{-3}$.

Keywords. Radon; alpha particle; lung cancer; CR-39; radon concentration; PAE; dose. 
In India few groups are engaged in indoor radon measurements (Khan et al 1988; Singh 1989; Subba Ramu et al 1991).

In this paper, preliminary measurements in the dwellings carried out at 18 different locations of Guwahati are presented. Guwahati, the Capital city of Assam $\left(26^{\circ} 16^{\prime} \mathrm{N}, 91^{\circ} 42^{\prime} \mathrm{E}\right)$, has an altitude of $110 \mathrm{~m}$ from the sea-level. In summer, temperature varies from a minimum of $20^{\circ} \mathrm{C}$ to a maximum of $37^{\circ} \mathrm{C}$ and in winter it varies from $10^{\circ} \mathrm{C}$ to $25^{\circ} \mathrm{C}$. The detector samples are placed in residential houses made of cement, brick, stone and sand.

\section{Experiment and measurement}

The experiment was carried out by exposing the small strips of size $1.2 \mathrm{~cm}^{2}$ of CR-39 plastic detector in aluminium dosimeter cups. A schematic diagram of the cup is given in figure 1 (Bhanti 1994).

It is a cylindrical aluminium cup partitioned by a latex membrane into two equal compartments. The dimension of each compartment thus formed are of height $3.5 \mathrm{~cm}$ and radius $2.95 \mathrm{~cm}$. One CR-39 film was mounted in the top of upper compartment for radon measurement. The perforated opening at the other end of the cup allows radon gas to permeate through a filter paper that retains the radon daughter products. The membrane helps to discriminate radon from thoron, permitting diffusion of $98 \%$ of radon into the aluminium cup as against $2 \%$ thoron due to their difference in half lives. The cups are calibrated in the Health Physics Division of BARC, Mumbai (Eappen 1994). The cups were exposed at 18 different locations in Guwahati for a period of 60 days for recording of tracks of alpha particles emitted from the decay of radon.

The exposed films were then etched in $6 \mathrm{~N} \mathrm{NaOH}$ solution for 6 hours at $70 \pm 1^{\circ} \mathrm{C}$. Alpha tracks emitted from radon recorded in the film were counted by using Lavo optical microscope under magnification of 400X. From these measurements, radon concentration is estimated by using the relation:

$$
C=\frac{T_{r}}{(6.7 \pm 0.5) \times 10^{-3}} \mathrm{~Bq} \mathrm{~m}^{-3}
$$

where $T_{r}$ is the track density, i.e., tracks per $\mathrm{cm}^{2}$.

\section{Results and discussion}

The results for the residential houses for different seasons and different locations (ground floor) are

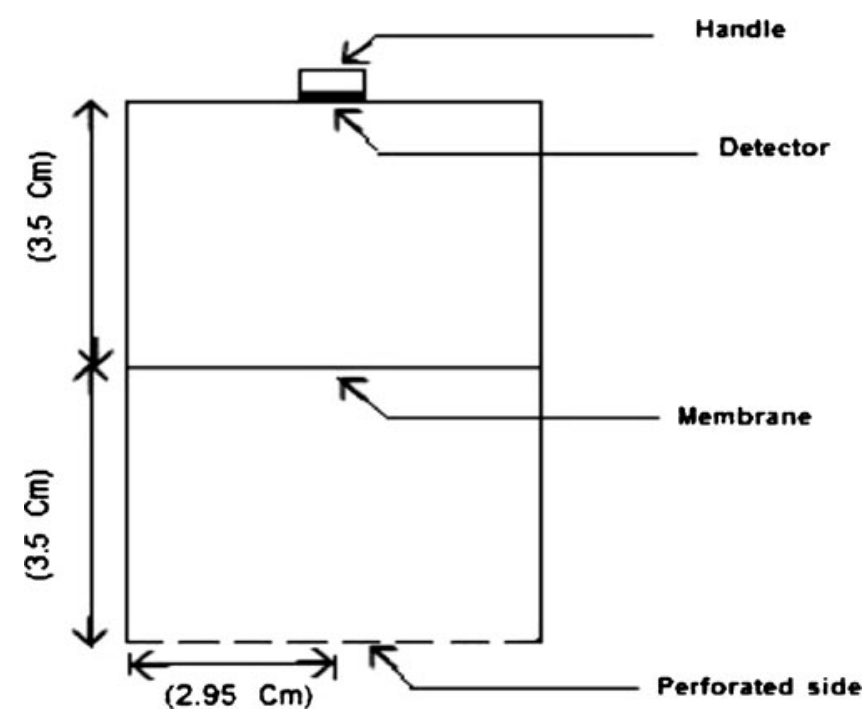

Figure 1. Schematics of the dosimeter cup.

given in table 1 . The minimum value of radon concentration is found to be $9.04 \mathrm{~Bq} \mathrm{~m}^{-3}$ and the maximum value is $43.16 \mathrm{~Bq} \mathrm{~m}^{-3}$. The average value for the total time is $21.31 \mathrm{~Bq} \mathrm{~m}^{-3}$.

The time integrated radon concentration is converted to radon daughter exposure. The potential alpha energy (PAE) expressed in WL (working level) is determined from the relation:

$$
\mathrm{PAE}=(\mathrm{F} / 3.7) \times \mathrm{Cav} \times 10^{-3} \mathrm{WL}
$$

where $\mathrm{F}=0.45$ is the equilibrium factor and $\mathrm{Cav}$ is the average radon concentration.

The potential alpha energy is found to be 2.59 mWL.

The time integral of the PAE concentration is expressed as working level month (WLM) where $1 \mathrm{WLM}$ is equivalent to $170 \mathrm{hr}$. Finally, it is converted into dose $(\mathrm{mSv})$ using the conversion factor $10 \mathrm{mSv}=1 \mathrm{WLM}$.

The average whole body dose is found to be 4.48 $\mathrm{mSv}$. Table 2 gives the radon level measurements in different parts of India (Kumar et al 1994).

It is observed that there is a significant increase in concentration during winter. However, the average radon concentration may be taken as the yearly average level. Increase in concentration during winter may be attributed to the presence of less air current in the atmosphere. It may also be due to the reason that the doors and windows remain closed for most part of the day, causing poor ventilation. To draw any conclusion regarding the increase of concentration during winter, measurement of radon concentration should be carried out for outdoor radon. An effort will be made to perform these experiments in future as further studies.

The maximum value of radon concentration is observed in Noonmati region. This region is having 
Table 1. Indoor radon concentration in $B q m^{-3}$ of residential houses in different locations of Guwahati in different seasons.

\begin{tabular}{llrrrr}
\hline Sample no. & \multicolumn{1}{c}{ Location } & April-May & June-July & Aug-Sept & Oct-Nov \\
\hline 1 & Pandu, New Colony & 20.73 & 20.54 & 21.63 & 23.02 \\
2 & Jalukbari & 10.47 & 10.58 & 15.07 & 24.32 \\
3 & Ananda Nagar & 18.13 & 25.74 & 22.30 & 27.80 \\
4 & Rest Camp & 9.04 & 29.92 & 26.16 & 30.15 \\
5 & Maligaon & 10.42 & 15.17 & 27.60 & 33.00 \\
6 & Gotanagar & 14.53 & 11.80 & 11.55 & 13.07 \\
7 & Bharalumukh & 17.56 & 16.92 & 25.80 & 27.51 \\
8 & Panbazar & 20.23 & 21.05 & 16.33 & 19.76 \\
9 & Guwahati Club & 17.28 & 16.97 & 19.00 & 24.26 \\
10 & Chandmari & 20.79 & 19.76 & 32.56 & 29.07 \\
11 & Zoo Road & 12.31 & 20.57 & 28.00 & 35.22 \\
12 & Noonmati & 24.38 & 36.75 & 32.97 & 43.16 \\
13 & Dispur & 13.00 & 31.76 & 23.28 & 24.09 \\
14 & Panjabari & 11.63 & 13.51 & 13.06 & 22.73 \\
15 & Beltola & 9.93 & 16.00 & 19.96 & 28.27 \\
16 & Bhangagarh & 11.27 & 24.26 & 28.03 & 36.21 \\
17 & Basistha & 12.55 & 16.72 & 19.40 & 18.67 \\
18 & Narengi & 13.08 & 21.19 & 15.06 & 19.93 \\
& Average & 14.86 & 20.50 & 23.13 & 26.74 \\
\hline
\end{tabular}

Table 2. Indoor radon levels in India.

\begin{tabular}{llcl}
\hline Location & \multicolumn{1}{c}{$\begin{array}{c}\text { Exposure mode and } \\
\text { calibration }\end{array}$} & $\begin{array}{c}\text { Radon concentration } \\
\left(\mathrm{Bq} \mathrm{m}^{-3}\right)\end{array}$ & $\begin{array}{c}\text { Average radon } \\
\text { concentration }\left(\mathrm{Bq} \mathrm{m}^{-3}\right)\end{array}$ \\
\hline Jodhpur & Cup with membrane & $85-133$ & - \\
Joduguda & Cup with membrane & $89-254$ & 150 \\
Calcutta & Cup with membrane & $11-36$ & 26 \\
Tamil Nadu & Cup with membrane & $40-55$ & 51 \\
Mumbai & Bare cup with membrane & $1.5-32$ & 11.6 \\
Guwahati (present work) & Cup with membrane & $9-43$ & 21.31 \\
\hline
\end{tabular}

a hill near it and it has also one Oil Refinery. There may be the possibility of emanation of radon from the oil which is being refined there.

\section{Acknowledgement}

The authors acknowledge with gratitude the research facility provided by Pandu College, Guwahati, Assam.

\section{References}

Archer V E, Wagoner J K and Lundin Jr F E 1973 Lung Cancer among uranium miners in United States; Health Phys. 23 351-371.

Bhanti D P 1994 Theoritical studies on calibration of SSNTDs for radon exposure; Bull. Radiat. Prot. 17(3\&4) 74-78.

Eappen K P 1994 Typical calibration facilities for radon/thoron monitoring using SSNTDs; Bull. Radiat. Prot. 17(3\&4) 84-89.
Khan A J, Sharma K C, Varshney A K, Prasad R and Tyagi R K 1988 Measurements of concentration of radon and its daughters in indoor atmosphere using CR-39 nuclear track detectors; Ind. J. Pure Appl. Phys. 26 425427.

Kumar S, Gopalani D and Jodha A S 1994 Indoor radon levels in India; Bull. Radiat. Prot. 17(3\&4) 41-45.

Lowder W M 1989 Natural environmental radioactivity and radon gas; In: Proc. International Workshop on Radon Monitoring in Radio Protection, Environmental Radio activity and Earth Sciences, ICTP Trieste, Italy, 3-14 April, pp. 1-17.

Pershagen G, Liang Z H, Hrubee Z, Svenson C and Boice Jr J D 1993 Residential radon exposure and lung cancer in Swedish Women; Health Phys. 63 179-186.

Sevc J, Kunz E and Placek V 1976 Lung cancer in uranium miners and long term exposure to radon daughter products; Health Phys. 30433.

Sevc J, Kunz E, Tomasek L, Placek V and Horacek J 1988 Cancer in man after exposure to Rn daughters; Health Phys. 54 27-46.

Singh N P 1989 Randon monitoring in Amritsar, India; In: Proc. Int. Workshop on Radon monitoring in Radio Protection, Environmental Radioactivity and Earth Sciences, ICTP Trieste, Italy, 3-14 April, pp. 490-503. 
Subba Ramu M C, Shaikh A N, Muraleedharan T S, Ramachandran T V and Nambi K S V 1991 Environmental radon monitoring in India: A plea for national effort; In: Proc. National Conf. Particle Tracks in Solids, Jodhpur (India), 9-11 October, p. 11.

UNSCEAR 1993 United Nations Scientific Committee on the Effect of Atomic Radiation, United Nation, New York.
Waxweiler R J, Roscoe R J, Archer V E, Thun M J, Wagoner J K and Lundin Jr F E 1981 Mortality follow up through 1977 of the white underground miners cohort examined by the United States Public Health Services; In: Radiation Hazards in Mining: Control, Measurement and Medical Aspects (ed.) Gomez M, American Institute of Mining, Metallurgical and Petroleum Engineers, New York.

MS received 5 July 2009; revised 23 July 2011; accepted 21 August 2011 